\title{
Smooth Muscle Myosin Heavy Chain Isoforms Are Developmentally Regulated in Male Fetal and Neonatal Sheep
}

\author{
JENNIFER CHERN, KRISTINE E. KAMM, AND CHARLES R. ROSENFELD \\ Departments of Pediatrics and Physiology, The University of Texas Southwestern Medical School, \\ Dallas, Texas 75235
}

\section{ABSTRACT}

Adult vascular smooth muscle expresses $204-\mathrm{kD}\left(\mathrm{SM}_{1}\right)$ and $200-\mathrm{kD}\left(\mathrm{SM}_{2}\right)$ myosin heavy chain (MHC) isoforms. Fetal vascular smooth muscle expresses another $200-\mathrm{kD}$ isoform, MHC-B, that appears to be developmentally regulated. The ontogeny of expression of these MHC isoforms in vascular and nonvascular smooth muscles is not fully understood and may differ. In the present report we examined the ontogeny of these isoforms in aortic and bladder smooth muscle from male fetal ( $n$ $=12,119-140-\mathrm{d}$ gestation; term $145 \pm 5 \mathrm{~d}$ ) and neonatal $(n=$ 12, 1-33 d) sheep. Tissues were analyzed for total and soluble protein contents. Actin, MHC, and MHC isoforms were analyzed by SDS-PAGE using 3-20\% and $4 \%$ polyacrylamide gels, respectively. The expression of the adult and fetal $200-\mathrm{kD}$ MHC isoforms were determined by Western analysis. Between $119 \mathrm{~d}$ gestation and $33 \mathrm{~d}$ neonatal, age-depende.t increases $(p<0.02)$ occurred in bladder actin ( $16 \pm 0.8$ versus $22 \pm 1.4 \mu \mathrm{g} / \mathrm{mg}$ of wet weight), MHC $(6.5 \pm 0.2$ versus $9.7 \pm 1.1)$ and both soluble (71 \pm 2.9 versus $92 \pm 6.3)$ and total protein $(78 \pm 3.9$ versus 103 $\pm 5.5)$. Aortic smooth muscle actin $(8.5 \pm 0.7$ versus $17 \pm 1.1)$, MHC (3.1 \pm 0.4 versus $5.2 \pm 0.5)$, and soluble ( $44 \pm 2.3$ versus $61 \pm 3.0)$ and total protein $(87 \pm 5.8$ versus $108 \pm 3.2)$ also

Smooth muscle lines the walls of hollow organs; it acts to resist an imposed load in the case of large arteries and to adjust organ caliber in the case of the bladder. Smooth muscle contraction results from the interaction of myosin in thick filaments with actin in thin filaments. The thick filament is an assembly of hundreds of individual myosin molecules, each composed of six polypeptide chains, two heavy chains, and two pairs of light chains. The carboxyl-terminal ends of two MHC wrap around each other, forming a coiled-coiled tail involved in filament assembly. The amino-terminal end of each MHC is

Received November 28, 1994; accepted June 22, 1995.

Correspondence and requests for reprints: Charles R. Rosenfeld, M.D., Department of Pediatrics, University of Texas, Southwestern Medical Center at Dallas, 5323 Harry Hines Blvd., Dallas, TX 75235.

Supported in part by National Institutes of Health Grant 5-RO1-HD08783.

Presented in part at the annual meeting of the Southern Society for Pediatric Research, New Orleans, LA, February 1994 increased $(p<0.01)$. Aortic $\mathrm{SM}_{1}$ increased $(r=0.79, p<$ 0.001 ) during this time, whereas expression of the $200-\mathrm{kD}$ MHC fell $(r=-0.79, p<0.001)$. In contrast, bladder $\mathrm{SM}_{1}$ fell $(r=$ $-0.88, p<0.001)$ as the $200-\mathrm{kD}$ MHC rose $(r=0.88, p<$ $0.001)$. The type of $200-\mathrm{kD}$ MHC isoform expressed also differed between tissue types; bladder expressed $\mathrm{SM}_{2}$ and little or no MHC-B throughout this phase of development, whereas fetal aorta appeared to express primarily MHC-B, which decreased as adult $\mathrm{SM}_{2}$ expression rose after birth. Expression of smooth muscle proteins and $\mathrm{MHC}$ isoforms are developmentally regulated and tissue-dependent, the latter perhaps reflecting developmental differences in organ growth and/or function. (Pediatr Res 38: 697-703, 1995)
MHC, myosin heavy chain

\section{Abbreviations}
$\mathrm{SM}_{1}, 204-\mathrm{kD}$ smooth muscle MHC
$\mathrm{SM}_{2}, 200-\mathrm{kD}$ smooth muscle MHC
$\mathrm{SM}_{\text {emb }}$, smooth muscle embryonic MHC
ANOVA, analysis of variance

folded into a globular head containing binding sites for actin and Mg-ATP as well as for each of the light chains. The head domain is the site of chemo-mechanical transduction associated with actin-activation of Mg-ATPase activity. Four major $\mathrm{MHC}$ isoforms have been reported to exist in vertebrate smooth muscle (1-4): $\mathrm{SM}_{1}$ (204 kD), $\mathrm{SM}_{2}$ (200 kD), MHC-B $(200 \mathrm{kD})$, and MHC-A (196 kD). SM 1 and $\mathrm{SM}_{2}$ are considered to be mature smooth muscle MHC isoforms, are co-expressed in a single smooth muscle cell (5), and are alternatively spliced products of a single gene differing in the carboxyl-terminal tail portion of the molecule $(2,6)$. MHC-A and MHC-B are referred to as nonmuscle $\mathrm{MHC}$ isoforms and are the products of different genes (7). However, all four MHC isoforms show high nucleotide and amino acid sequence homology to each other $(3,7)$. Although expression of the $\mathrm{SM}_{1}$ and $\mathrm{SM}_{2}$ isoforms is associated with the "contractile" phenotype of smooth muscle, recent studies indicate that expression of the nonmuscle 
isoforms occurs in smooth muscle cells undergoing growth and/or cell division, that is, cells of the "synthetic" phenotype $(7,8)$.

The expression of the various $\mathrm{MHC}$ isoforms in smooth muscle appears to be developmentally regulated. In aortic smooth muscle from fetal, neonatal and adult rabbits, mRNA for $\mathrm{SM}_{1}$ is present in abundance (5). In contrast, $\mathrm{SM}_{2}$ mRNA is undetectable in fetal rabbit aorta and barely detectable in the neonate; however, beyond the neonatal period its expression increases as the rabbit matures (5). In the human aorta both $\mathrm{SM}_{1}$ and $\mathrm{SM}_{2}$ mRNA are detectable at $31 \mathrm{wk}$ of gestation and increase after birth (9). MHC-B, which also has been referred to as bovine brain MHC (10), chicken fibroblast FMHC (11), and $\mathrm{SM}_{\mathrm{emb}}$ (3), is expressed most predominantly in the fetal rabbit and human aorta and expression decreases after birth (3, $9,12)$. It is also found in the adult brain, testis, lung, kidney, arteriosclerotic neointimas, and cultured smooth muscle cells $(3,7)$. MHC-A was initially identified in human platelets (4, 13). Subsequently it was observed in aortic smooth muscle from neonatal rats (14) and the bovine fetus (15) and was reported to decrease with increasing age. Its presence, however, in fetal rabbit aorta is questionable $(3,16)$. MHC-A is also expressed in cultured aortic smooth muscle cells, fetal rat skin fibroblasts, and rat platelets $(4,15)$. Although the function of the various $\mathrm{MHC}$ isoforms is not well defined, differences in their expression may provide an index of smooth muscle development and/or maturation of function.

Sheep have been used to study various aspects of fetal physiology (17-19). This reflects not only the large size of the fetus, which permits instrumentation and thus "direct" studies in utero, but also the relatively long duration of gestation, 145 $\pm 5 \mathrm{~d}$, which more easily allows the study of specific time points during development than in smaller species, e.g. rat and rabbit $(5,14)$. Because of the advantages of using fetal sheep, its utility in studying cardiovascular development, and our ability to modify the hormonal milieu (18) or the time of parturition (19), we examined the patterns of the MHC isoform expression and protein content in vascular and nonvascular smooth muscle tissues obtained from male fetal and neonatal sheep. We show that alterations in actin, MHC, and soluble and total protein contents as well as $\mathrm{MHC}$ isoform expression are not only developmentally regulated, but also tissue-dependent.

\section{METHODS}

Tissue preparation. Male fetal (119-140 d of gestation, $n=$ 12 ; term $145 \pm 5 \mathrm{~d})$ and neonatal $(1-33 \mathrm{~d}, n=12)$ sheep were killed by a rapid i.v. bolus infusion of sodium pentobarbital ( 50 $\mathrm{mg} / \mathrm{kg}$ ) to either the mother in the case of the fetus or the newborn via the external jugular vein. Segments of abdominal aorta and the entire bladder were quickly removed from each animal and placed into iced physiologic buffered solution $\left(137.0 \mathrm{mM} \mathrm{NaCl}, 2.7 \mathrm{mM} \mathrm{KCl}, 10 \mathrm{mM} \mathrm{Na}{ }_{2} \mathrm{HPO}_{4}, 1.76 \mathrm{mM}\right.$ $\mathrm{KH}_{2} \mathrm{PO}_{4}, 0.1 \%$ diethyl pyrocarbonate, $\mathrm{pH} 7.4$ ), which was bubbled with oxygen. Endothelium and adventitia were removed from the aorta with a soft cotton swab and blunt dissection, respectively, and epithelium was removed from the bladder by sharp dissection. Strips of tissue were cut, blotted dry to remove excess water and capillary blood, frozen in liquid nitrogen, and stored at $-60^{\circ} \mathrm{C}$ until studied. When we examined the effect of blotting on sample weight, the coefficient of variation was $<4 \%$. These studies were approved by the Institutional Review Board for Animal Research.

Protein analysis and content. SDS homogenates were prepared from 10-20-mg samples of frozen tissue using methods previously reported $(20,21)$. The homogenates were divided into two aliquots. One was subjected to centrifugation at $10000 \times g$ for $2 \mathrm{~min}$, and the supernatant was removed to determine the soluble or cellular protein in each sample. The other sample was not centrifuged and thus was used to determine the "total" homogenate protein, i.e. the sum of the soluble and nonsoluble fractions. Aliquots of both samples were analyzed for protein content by BCA reagent (Pierce, Rockford, IL). Additional aliquots of each sample containing bromphenol blue were subjected to SDS-PAGE, using 3-20\% and 4\% polyacrylamide gels to determine the contents of total actin and $\mathrm{MHC}$ and the relative amounts of $\mathrm{MHC}$ isoforms, respectively. This method permits accurate analysis of all proteins up to 500 $\mathrm{kD}$ in the gradient gel. For each tissue, minigels were prepared and loaded with $20-40 \mu \mathrm{g}$ of soluble protein, and the samples were subjected to electrophoresis at $100 \mathrm{~V}$ until the dye front was no longer evident in the loading gel and at $200 \mathrm{~V}$ until the dye front reached the bottom of the gel. Each gel also contained lanes for high and low molecular weight standards, which permitted determination of molecular mass (Bio-Rad Laboratories, Richmond, CA). Gels were stained overnight with Coomassie Brilliant Blue and appropriately destained to remove background staining. To estimate the relative amounts of actin, $\mathrm{MHC}$, and $\mathrm{MHC}$ isoforms, the areas under the peaks on each stained band were scanned in duplicate with a laser densitometer (model 2202, LKB instruments, Inc., Stockholm, Sweden), and the absorbance recorded by a 2220 LKB recorder with integrator (21). Differences between measurements were generally less than $5 \%$, and the values for each band were averaged. The fraction of stained protein accounted for by actin and $\mathrm{MHC}$ were converted to micrograms using the total protein quantified by BCA reagent in each sample. Values are expressed as micrograms/mg of wet weight.

Antibody production. Two peptides of 9 amino acids were synthesized based on the derived amino acid sequences of the carboxyl-terminal ends of the $200-\mathrm{kD}$ nonmuscle $\mathrm{MHC}$ isolated from bovine brain (INETQPPQS) (10) and the 200-kD adult smooth muscle $\mathrm{MHC}\left(\mathrm{SM}_{2}\right)$ isolated from rabbit aorta (GPPPQETSQ) (1). The former also has been isolated from fetal smooth muscle and has been referred to as $\mathrm{SM}_{\mathrm{emb}}$ or MHC-B (3). The peptides were conjugated to tuberculin purified protein derivative with glutaraldehyde, and rabbits were immunized and bled by the Animal Resources Center, UT Southwestern Medical Center. The antisera were characterized for specificity by Western analysis using purified bovine brain myosin (a gift of Barbara Barylko), which is specific for MHC-B, and partially purified bovine tracheal smooth muscle myosin or adult myometrium, which do not express MHC-B, but do express $\mathrm{SM}_{2}$ (22). The specificity of the two antisera is illustrated in Fig. 1, where the absence of cross-reactivity is clearly seen. 


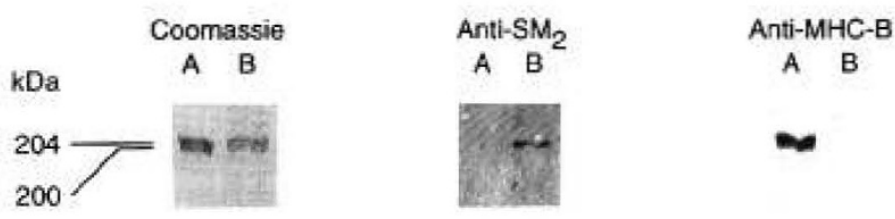

Figure 1. Immunoblots demonstrating specificity of anti-SM $\mathrm{S}_{2}$ and antiMHC-B antisera. Lanes $A$ and $B$ contain purified bovine brain myosin and adult myometrial myosin, respectively. Proteins were subjected to electrophoresis in a $4 \%$ polyacrylamide gel, then transferred to nitrocellulose for immunoblotting.

SDS-PAGE and immunoblotting. Using the extracts of fetal and neonatal bladder and aortic smooth muscle, $\sim 800 \mathrm{ng}$ of total $\mathrm{MHC}$ were loaded and separated on $4 \%$ polyacrylamide gels. Large amounts of total MHC were loaded to improve detection of minor components of the MHC population. Proteins were electrophoretically transferred to nitrocellulose paper at $80 \mathrm{~mA}$ overnight in the presence of methanol $(20 \%)$ and SDS $(0.1 \%)$. Blots were then blocked for $1 \mathrm{~h}$ in buffer that contained powdered milk $(0.3 \% \mathrm{wt} / \mathrm{vol})$, incubated for $4 \mathrm{~h}$ with blocking buffer containing antiserum (1:1000) against either $\mathrm{SM}_{2}$ or MHC-B, and then incubated with goat anti-rabbit IgG conjugated with horseradish peroxidase (1:1000). Regions containing $\mathrm{MHC}$ isoforms were visualized after incubation with 4-chloro-1-naphthol (21).

Statistics. Data across time were analyzed using linear regression analysis by the least squares method. To determine where in development significant changes may have occurred animals were divided into four groups, which reflect known alterations in the hormonal milieu of fetal sheep or delivery and postnatal development: <128-d gestation $(n=6)$, 130-145-d gestation $(n=6), \leq 1 \mathrm{wk}$ after birth $(n=6)$, and 3-4 wk after birth $(n=6)$. We then used multiple comparisons by ANOVA. When significance was observed by ANOVA at $p<0.05$, the Newman-Keuls test was used to determine differences between groups. Data are presented as the mean and 1 SEM.

\section{RESULTS}

Total and soluble protein, actin, and MHC contents. Bladder smooth muscle total protein increased significantly ( $p=$ 0.003 ) during the period of ovine development studied (Fig. $2 A$ ), values rising from $78.5 \pm 3.9 \mu \mathrm{g} / \mathrm{mg}$ of wet weight in fetal sheep $<128 \mathrm{~d}$ gestation to $103 \pm 5.5 \mu \mathrm{g} / \mathrm{mg}$ of wet weight in neonates $>20 \mathrm{~d}$ old. The amount of soluble protein (Fig. $2 B)$ increased $(p=0.007)$ in a similar fashion $(71.0 \pm$ 2.9 to $92.2 \pm 6.3$ ). In both instances fetal and neonatal groups were significantly different ( $p \leq 0.01$, ANOVA). In the aorta, total protein content rose $(p=0.015)$ from $86.5 \pm 5.8$ to 108 $\pm 3.2 \mu \mathrm{g} / \mathrm{mg}$ of wet weight during the period of development examined (Fig. 2C), whereas the content of soluble protein (Fig. $2 D)$ increased $(p<0.001)$ from $44.1 \pm 2.3$ to $60.6 \pm 3.0$ $\mu \mathrm{g} / \mathrm{mg}$ of wet weight. As with the bladder, aortic soluble protein was significantly higher after birth $(p=0.003$, ANOVA), whereas changes in total protein were more gradual across time. Although the relative rise in bladder total and soluble protein was similar, 32 and $30 \%$, respectively, the

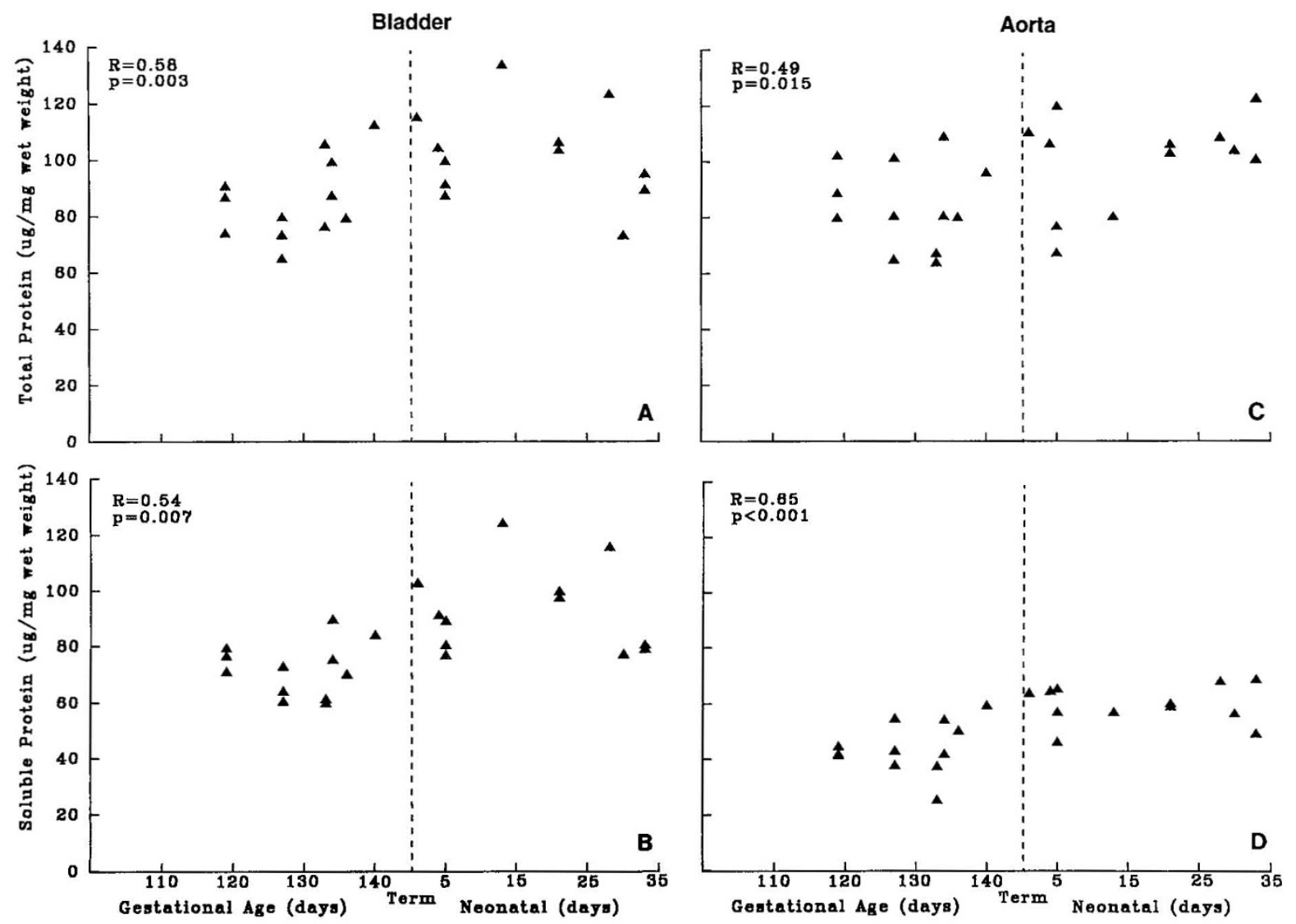

Figure 2. Developmental changes in bladder and aortic smooth muscle contents of total $(A$ and $C)$ and soluble $(B$ and $D)$ protein in fetal and neonatal sheep. 
relative rise in aortic total protein was 24 versus $39 \%$ for aortic soluble protein.

In concert with the increases in tissue protein content, total bladder actin content also rose significantly $(p=0.013)$ during the fetal-neonatal period (Fig. $3 A$ ), increasing $37 \%$ from 16.1 \pm 0.8 to $22.1 \pm 1.4 \mu \mathrm{g} / \mathrm{mg}$ of wet weight. Bladder $\mathrm{MHC}$ content (Fig. 3B) increased $(p<0.001)$ in a parallel fashion, values rising $49 \%$ from $6.51 \pm 0.23$ to $9.72 \pm 1.1 \mu \mathrm{g} / \mathrm{mg}$ of wet weight. In both instances values were significantly higher after birth ( $p \leq 0.03$, ANOVA). As in the bladder, total actin content in the aorta also rose (Fig. $3 C$ ), values increasing $(p<$ 0.001 ) from $8.50 \pm 0.65 \mu \mathrm{g} / \mathrm{mg}$ of wet weight at $<128 \mathrm{~d}$ of gestation to $16.7 \pm 1.1$ in neonates $>20$ d postdelivery. Aortic MHC content followed a similar pattern (Fig. 3D), values increasing $(p=0.002)$ from $3.12 \pm 0.38$ to $5.23 \pm 0.46$ $\mu \mathrm{g} / \mathrm{mg}$ of wet weight. Again, contents in aortic MHC and actin were greater after birth ( $p<0.04$, ANOVA).

MHC isoforms. The relative amounts of the 204- and 200-kD MHC isoforms present in the samples of smooth muscle were quantified from densitometric scans of the proteins separated on $4 \%$ polyacrylamide gels. Only two $\mathrm{MHC}$ bands were observed on each scan for each tissue studied, i.e. bladder and aortic smooth muscle (Fig. 4). We observed no bands at $196 \mathrm{kD}$ at any time in development for either tissue. The proportion of the 204-kD MHC expressed in bladder smooth muscle fell gradually throughout development (Fig. $5 A ; p<0.001$ ), levels decreasing $\sim 27 \%$, whereas the relative expression of the $200-\mathrm{kD}$ MHC(s) increased $77 \%$ (Fig. $5 B ; p<$

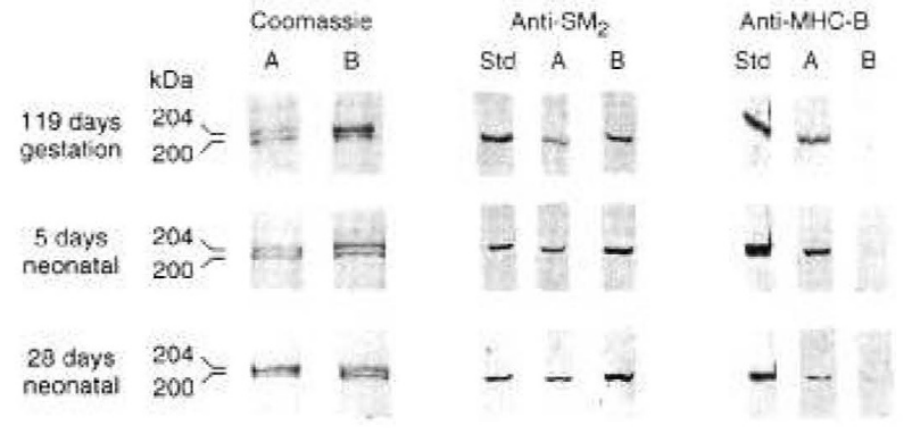

Figure 4. Representative immunoblots of $200 \mathrm{kD}$ myosin heavy chain isoforms in aorta $(A)$ and bladder $(B)$ from fetal and neonatal male sheep. The standards for the anti-SM $\mathrm{SM}_{2}$ and anti-MHC-B were partially purified tracheal myosin and purified bovine brain myosin, respectively. Approximately $800 \mathrm{ng}$ of myosin heavy chain were loaded in each lane.

0.001 ). Thus, the ratio of $204: 200-\mathrm{kD}$ MHC in bladder smooth muscle decreased from $>2.8$ in fetal sheep to $\sim 1$ in 3-4-wkold neonates.

The pattern of expression of MHC isoforms in the aortic smooth muscle was opposite that observed in the bladder smooth muscle. That is, between $119 \mathrm{~d}$ of gestation and 33 d postdelivery, the relative amount of aortic smooth muscle 204-kD MHC rose dramatically, values increasing from $44 \%$ of the MHC to $67 \%$ in the older neonate (Fig. $5 \mathrm{C} ; p<$ $0.001)$. As expected, the proportion of $\mathrm{MHC}$ represented by the $200-\mathrm{kD}$ protein fell (Fig. 5D). Thus, the ratio of
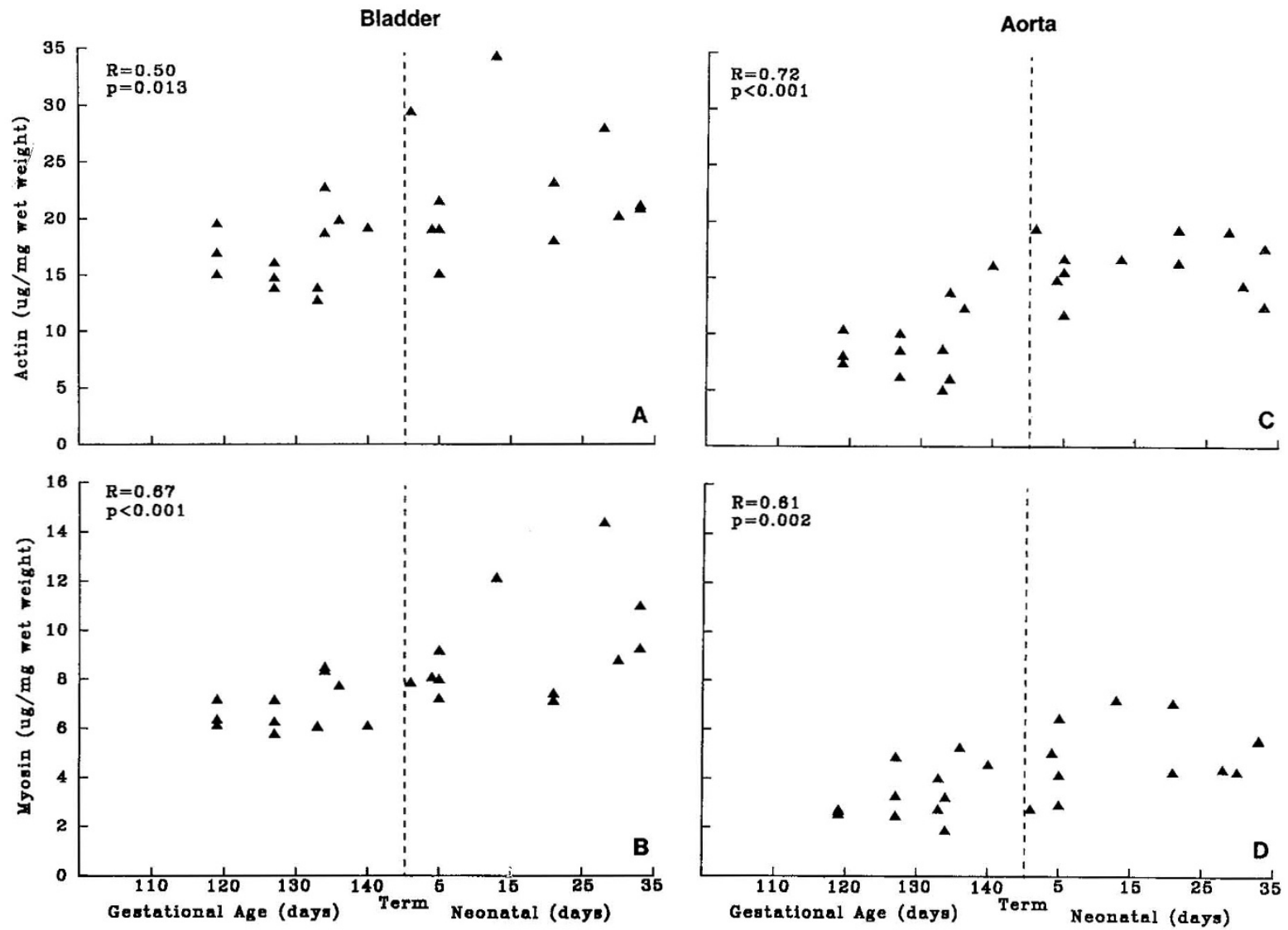

Figure 3. Developmental changes in bladder and aortic smooth muscle contents of actin $(A$ and $C)$ and myosin heavy chain $(B$ and $D)$ in fetal and neonatal sheep. 


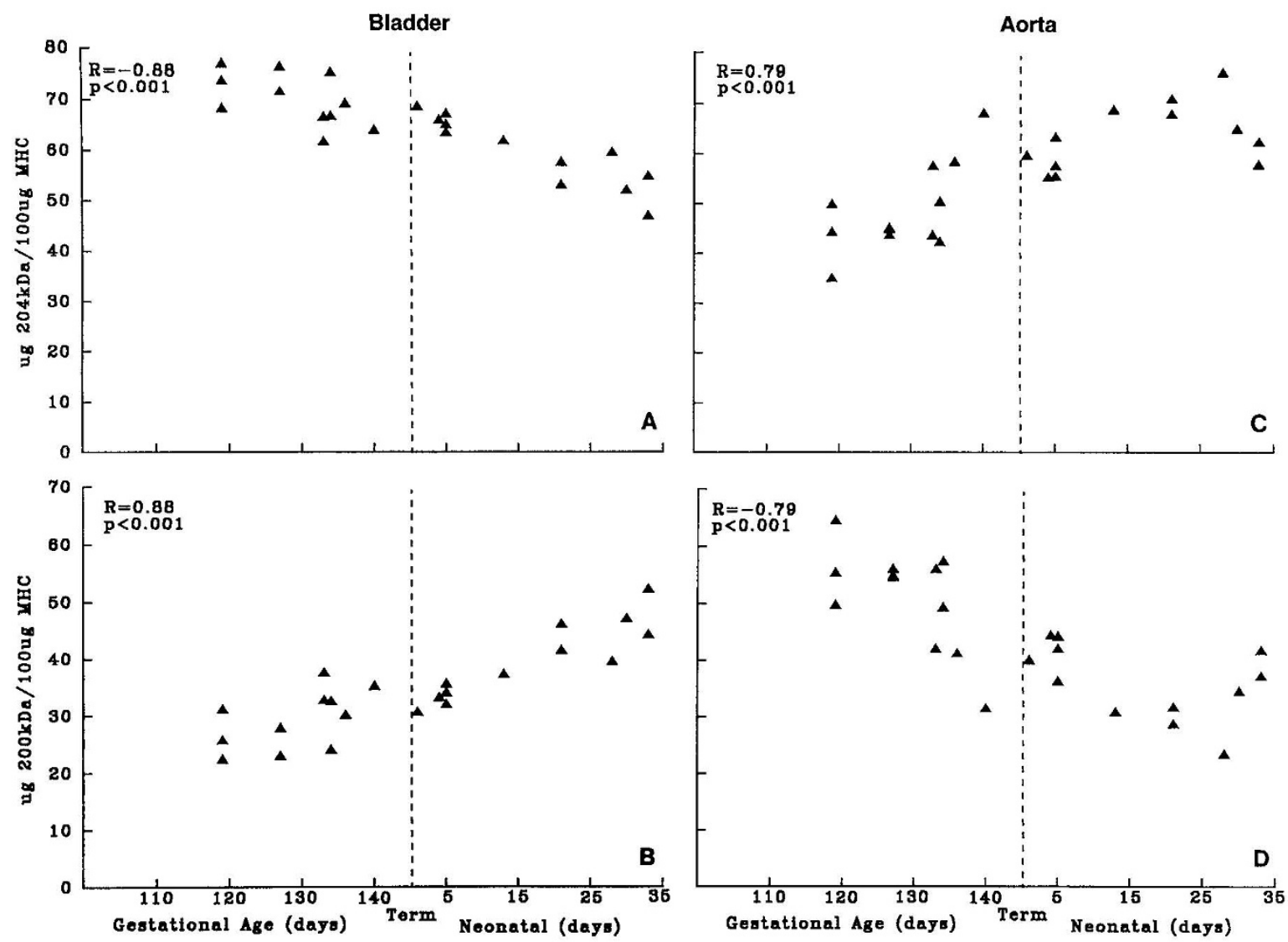

Figure 5. Developmental alterations in the bladder and aortic smooth muscle expression of 204-kD myosin heavy chain isoform $(A$ and $C$ ) and $200-\mathrm{kD}$ myosin heavy chain isoforms $(B$ and $D)$ in fetal and neonatal sheep.

204:200-kD MHC in aorta rose from $<1$ in the fetal sheep to $>2$ in neonates at $\geq 20 \mathrm{~d}$.

Because the $200-\mathrm{kD}$ MHC could represent either the adult smooth muscle isoform $\left(\mathrm{SM}_{2}\right)$ or the fetal isoform (MHC-B), which comigrate and cannot be separated by SDS-PAGE, we performed Western immunoblot analyses on each tissue sample using specific antisera (see Methods). In fetal aortic smooth muscle, MHC-B appeared to be the predominant $200-\mathrm{kD}$ MHC isoform expressed (Fig. 4); furthermore, the expression of this isoform appeared to decrease during development as expression of the adult $\mathrm{SM}_{2}$ rose. In contrast, the bladder smooth muscle primarily expressed the adult $\mathrm{SM}_{2}$ isoform throughout the period of development examined, and little or no fetal MHC-B was observed in either the fetal or neonatal sheep bladder (Fig. 4).

\section{DISCUSSION}

Although several investigators have examined the expression of $\mathrm{MHC}$ isoforms and other proteins in smooth muscle during development, the extent of these studies has been limited by the brevity of the gestational period, the size of the fetus, or the apparent availability of sufficient tissues for study at multiple points in gestation $(3-5,9,12,14)$. In contrast, fetal sheep have a relatively long gestation (145 d) and at term weigh 3-4 kg; thus adequate amounts of tissue are available as early as $40-50 \%$ of gestation. In the present study we obtained tissues throughout the last $3 \mathrm{wk}$ of ovine pregnancy and the first month after birth. We have characterized the alterations in the contents of actin and total MHC in vascular smooth muscle and bladder, a nonvascular of smooth muscle, during this portion of ovine development. Moreover, we have performed parallel studies demonstrating that the pattern of MHC isoform expression is also developmentally regulated and tissue specific in fetal and neonatal sheep.

In the present study the actin and MHC contents in bladder and aortic smooth muscle increased during the period of development studied. Although the actin/myosin weight ratios were similar in the two tissues and were unchanged, i.e. remaining $\sim 3.0$ and $\sim 2.5$, respectively, the relative rise in actin and myosin contents in aorta was nearly twice that seen in the bladder. Thus, it was not until $30 \mathrm{~d}$ neonatal that aortic content of both proteins equaled that seen in the fetal bladder at $<128$-d gestation. This rise in the content of contractile proteins was associated with parallel increases in total and soluble (or cellular) protein contents in both bladder and aorta. It is notable, however, that the increases in bladder total and soluble protein were similar, $\sim 30 \%$, whereas the relative rise in aortic soluble protein was $\sim 40 \%$ compared with $\sim 24 \%$ for total protein content. Furthermore, although soluble protein accounted for $\sim 90 \%$ of total bladder protein, it accounted for only $50-60 \%$ of the total protein in the aorta. These differences in the amounts of cellular protein in the bladder and aorta likely reflect a greater content of extracellular proteins such as elastin and collagen in the aorta and suggest that aortic growth may primarily reflect increases in smooth muscle content. 
Alterations in smooth muscle tissue contractile proteins have been related to alterations in tissue stress generation $(21,23$, 24). Annibale et al. (21) observed increased amounts of actin, $\mathrm{MHC}$, and total protein contents in the uterine artery of sheep during pregnancy and postulated that this may explain the increase in stress generation of uterine artery smooth muscle seen during pregnancy $(23,25,26)$. As noted above, the contents of actin and myosin in aorta from younger fetuses were about half that seen in neonates at $30 \mathrm{~d}$, which may result in lower stresses in aortas of younger, less developed animals. If similar alterations in the contents of contractile proteins occur in smaller muscular arteries, this potentially could contribute to the reduced systemic pressor responses to agonists reported in fetal versus adult sheep $(27,28)$ and possibly the lower mean arterial pressure in early fetal versus neonatal sheep (29). The turnover of contractile proteins in the adult bladder is rapid and can be quickly regulated in response to changing demands, e.g. in the presence of urethral obstruction (24). Although urine output is relatively constant per $\mathrm{kg}$ of fetal weight during ovine gestation (17), urine volume and thus bladder distention would increase with age, especially after delivery. Therefore, there is a need for enhanced bladder function and stress generation, which may be associated with the increases in actin and MHC contents observed across development. Thus the changes in contractile protein contents observed in the aorta and bladder may reflect the changing functional demands of these tissues during development. Future studies will include measurements of contractile proteins earlier in fetal development and investigation of aortic and bladder smooth muscle stresses to test this thesis. In addition, alterations in the hormonal milieu before and after delivery may modify contents of contractile proteins, as recently observed in myometrium of cycling ewes (22). This, however, remains to be proven.

Results of the present investigation indicate that MHC isoform expression in smooth muscle is not only developmentally regulated, but that patterns of expression differ between tissues within a species. In adult animals and humans the predominant MHC isoforms in smooth muscle are $\mathrm{SM}_{1}$ and $\mathrm{SM}_{2}(2,9,12$, $15,16,20,22)$. Although nonmuscle $\mathrm{MHC}$ isoforms have been observed in aortic smooth muscle from adult animals and humans $(9,12,14)$, they are not present in adult bovine (15) or rabbit (16) aorta or adult ovine uterine artery, myometrium or bladder (22), which may reflect species differences. During development $\mathrm{SM}_{1}$ is expressed to varying but significant extent in several smooth muscle tissues from the fetus and neonate (3, $5,9,12,14-16,30$ ), whereas the composition of the remaining MHC is variable. However, it has become more evident that the predominant lower molecular weight species expressed in fetal and neonatal aorta are the nonmuscle MHC isoforms, which only can be identified using Western analysis because of their similar electrophoretic mobilities $(9,12,15,16)$. In the rabbit (3) and human $(9,12)$ MHC-B is the predominant isoform expressed in fetal aorta, with the $\mathrm{SM}_{2}$ isoform subsequently appearing in small amounts late in gestation or during the neonatal period. In the 3-d newborn rat MHC-A accounted for $\sim 30 \%$ of total $\mathrm{MHC}$ and decreased with increasing age (14). MHC-B was not assessed. Although these studies provide substantial insight into the ontogeny of MHC expression in smooth muscle, they are somewhat limited by large gaps in time between samples, the study of relatively few samples at each period of development, and little or no parallel data regarding the tissue contents of these proteins.

In the present study, a MHC band was not observed at 196 $\mathrm{kD}$ on $4 \%$ polyacrylamide gels in either fetal or neonatal bladder or aorta, an observation consistent with our findings in adult sheep (22). However, we observed tissue-specific patterns of expression of both the 204- and 200-kD MHC isoforms during the fetal and neonatal periods. In the bladder, $\mathrm{SM}_{1}$ was the predominant $\mathrm{MHC}$ isoform expressed until near the end of the neonatal period; results are consistent with those observed in rat bladder (14). $\mathrm{SM}_{2}$ accounted for the majority, if not all, of the $200-\mathrm{kD}$ isoform and was present throughout development, expression increasing $\sim 2$-fold, whereas $\mathrm{SM}_{1}$ decreased. Similar alterations have been seen in tracheal smooth muscle from neonatal and large adult pigs (30). In contrast, at $\sim 120$-d gestation the ovine fetal aorta expressed smaller amounts of $\mathrm{SM}_{1}$ than the $200-\mathrm{kD}$ MHC isoform, which appears to be predominantly MHC-B. However, after birth, aortic expression of MHC-B appears to decrease and is replaced by increasing amounts of both $\mathrm{SM}_{1}$ and $\mathrm{SM}_{2}$. Thus, in the developing sheep both adult MHC isoforms are present in the tissues studied, whereas MHC-B is expressed only in vascular smooth muscle. Although the switch between MHC-B and $\mathrm{SM}_{2}$ expression in the fetal ovine aorta is consistent with that reported in the rabbit and human $(5,9,12)$, the absence of MHC-B expression in the developing bladder is a novel observation and leads us to conclude that MHC isoform expression is developmentally regulated and differs between tissues within a species. Similar conclusions have been made by Frid et al. (31) in studies of calponin and caldesmon, two additional contractile proteins, in aorta and nonvascular smooth muscle from human abortuses.

The role of the various MHC isoforms in smooth muscle function remains unclear. Although MHC-B has high homology with $\mathrm{SM}_{1}$ and $\mathrm{SM}_{2}$, its function appears to be different. MHC-B is expressed not only in the fetal aorta, but also in cultured vascular smooth muscle cells and proliferating smooth muscle cells within arteriosclerotic neointimas (3). Thus it may be integral in smooth muscle proliferation, growth or migration. In support of this notion, antisense nonmuscle MHC oligonucleotides, which depress protein expression, suppress smooth muscle cell proliferation in vitro (32). When MHC-B is expressed in proliferating cultured smooth muscle cells there is a phenotypic change from spindle-shaped cells capable of contraction to polygonal cells with an increased amount of subcellular organelles involved with protein synthesis. These cells also lose their thick filaments and have a decreased capacity to contract (33), which may be proportionate to the expression of the nonmuscle MHC (8). Therefore, MHC-B may constitute a marker for the synthetic state of smooth muscle cells $(3,7,33)$. It is notable, however, that MHC-B was only observed in the aorta of fetal and neonatal sheep, but not in the bladder, which may be consistent with our speculation that the smooth muscle content of bladder is more developed at $128 \mathrm{~d}$ gestation than that of the aorta. If indeed the presence of the MHC-B isoform reflects the proliferative activity of a 
particular smooth muscle, how then does the urinary bladder grow late in development? Because the fetal bladder is quite functional at $\sim 120 \mathrm{~d}$ gestation, its contractile phenotype may be established much earlier in gestation than studied, and subsequent growth reflects cellular elongation and hypertrophy.

Although we have not determined a regulatory mechanism for the observed changes in the expression of the various MHC isoforms examined in the present study, it is evident that these changes occurred gradually throughout the period of development investigated. Because there were no abrupt alterations in proteins in either the aorta or bladder associated with parturition and delivery, it is unlikely that a placental factor is primarily involved. Nonetheless, the process observed is well orchestrated and appears to proceed in an orderly manner. This suggests that the regulatory factor or factors involved may simultaneously affect each of the genes expressing these isoforms, but that the responses differ; that is, they increase or decrease the production of the specific gene product. Moreover, patterns of isoform expression differ between tissues, indicating differing regulatory paradigms during development. Future studies will be directed toward understanding these regulatory mechanisms.

Acknowledgment. The authors express their appreciation and thanks to Susan Battle-Brown who assisted in the preparation of the manuscript.

\section{REFERENCES}

1. Nagai R, Larson DM, Periasamy M 1988 Characterization of a mammalian smooth muscle myosin heavy chain cDNA clone and its expression in various smooth muscle types. Proc Natl Acad Sci USA 85:1047-1051

2. Nagai R, Kuro-o M, Babij P, Periasamy M 1989 Identification of two types of smooth muscle myosin heavy chain isoforms by cDNA cloning and immunoblot analysis. $\mathrm{J}$ Biol Chem 264:9734-9737

3. Kuro-o M, Nagai R, Nakahara $K$, Katoh $H$, Tsai R, Tsuchimochi $H$, Yazaki $Y$, Ohkubo A, Takaku F 1991 cDNA cloning of a myosin heavy chain isoform in embryonic smooth muscle and its expression during vascular development and in arteriosclerosis. J Biol Chem 266:3768-3773

4. Kawamoto S, Adelstein R 1987 Characterization of myosin heavy chains in cultured aorta smooth muscle cells. J Biol Chem 262:7282-7288

5. Kuro-o M, Nagai R, Tsuchimochi, H, Katoh, H, Yazaki Y, Ohkubo A, Takaku, F 1989 Development-ally regulated expression of vascular smooth muscle myosin heavy chain isoforms. J Biol Chem 264:18272-18275

6. Eddinger TJ, Murphy RA 1988 Two smooth muscle myosin heavy chains differ in their light meromyosin fragment. Biochemistry 27:3807-3811

7. Simons M, Wang M, McBride W, Kawamoto S, Yamakawa K, Gdula D, Adelstein RS, Weir L 1991 Human nonmuscle myosin heavy chains are encoded by two genes located on different chromosomes. Circ Res 69:530-539

8. Seidel CL, Rickman D, Steuckrath H, Allen JC, Kahn AM 1991 Control and function of alterations in contractile protein isoform expression in vascular smooth muscle. In: Moreland, RS (ed) Regulation of Smooth Muscle Contraction. Plenum Press, New York, pp 315-325
9. Aikawa M, Sivan PN, Kuro-o M, Kimura K, Nakahara K, Takewaki S, Ueda M, Yamaguchi H, Yazaki Y, Periasamy M, Nagai R 1993 Human smooth muscle myosin heavy chain isoforms as molecular markers for vascular development and atherosclerosis. Circ Res 73:1000-1012

10. Murakami N, Healy-Louie G, Elzinga M 1990 Amino acid sequence around the serine phosphorylated by casein kinase II in brain myosin heavy chain. J Biol Chem 265:1041-1047

11. Katsuragawa Y, Yanagisawa M, Inoue A, Masaki T 1989 Two distinct nonmuscle myosin-heavy-chain mRNAs are differentially expressed in various chicken tissues. Eur J Biochem 184:611-616

12. Frid MG, Printesva OY, Chiavegato A, Faggin E, Scatena M, Kotcliansky VE, Pauletto P, Glukhova MA, Sartore S 1993 Myosin heavy-chain isoform composition and distribution in developing and adult human aortic smooth muscle. J Vasc Res 30:279-292

13. Adelstein RS, Pollard TD, Kuehl WM 1971 Isolation and characterization of myosin and two myosin fragments from human blood platelets. Proc Natl Acad Sci USA 68:2703-2707

14. Eddinger TJ, Murphy RA 1991 Developmental changes in actin and myosin heavy chain isoform expression in smooth muscle. Arch Biochem Biophys 284:232-237

15. Zanellato AMC, Borrione AC, Giuriato L, Tonello M, Sannapieco G, Pauletto P, Sartore S 1990 Myosin isoforms and cell heterogeneity in vascular smooth muscle. I. Developing and adult bovine aorta. Dev Biol 141:431-446

16. Borrione AC, Zanellato AMC, Scannapieco G, Pauletto P, Sartore S 1989 Myosin heavy-chain isoforms in adult and developing rabbit vascular smooth muscle. Eur $\mathrm{J}$ Biochem 183:4132-4137

17. Brace RA 1986 Amniotic fluid volume and its relationship to fetal fluid balance: review of experimental data. Semin Perinatol 10:103-112

18. Andujo O, Nielsen H, Rosenfeld CR, Snyder JM 1987 Failure to detect a stimulatory effect of estradiol-17 $\beta$ on ovine fetal lung maturation. Pediatr Res 22:145-149(abstr)

19. France JT, Magness RR, Murray BA, Rosenfeld CR, Mason JI 1988 The regulation of ovine placental steroid $17 \alpha$-hydroxylase and aromatase by glucocorticoid. Mol Endocrinol 2:193-199

20. Rovner AS, Thompson MM, Murphy RA 1986 Two different heavy chains are found in smooth muscle myosin. Am J Physiol 250:C861-C870

21. Annibale DJ, Rosenfeld CR, Stull JT, Kamm KE 1990 Protein content and myosin light chain phosphorylation in uterine arteries during pregnancy. Am J Physiol 259:C484-C489

22. Rosenfeld CR, Kamm KE 1993 Myosin heavy chain isoforms are regulated differently in myometrium and uterine artery smooth muscle in ovine pregnancy and the puerperium. Biophys J 64:A34

23. Annibale DJ, Rosenfeld R, Kamm KE 1989 Alterations in vascular smooth muscle contractility during ovine pregnancy. Am J Physiol 25:H1282-H1288

24. Malmqvist U, Arner A, Uvelius B 1991 Contractile and cytoskeletal proteins in smooth muscle during hypertrophy and its reversal. Am J Physiol 260:C1085-C1093

25. D'Angelo G, Osol G 1993 Regional variation in resistance artery diameter responses to $\alpha$-adrenergic stimulation during pregnancy. Am J Physiol 264:H78-H85

26. Moisey DM, Tulenko T 1983 Increased sensitivity to angiotensin in uterine arteries from pregnant rabbits. Am J Physiol 244:H335-H3340

27. Yoshimura T, Magness RR, Rosenfeld CR 1990 Angiotensin II and $\alpha$-agonist I. Responses of ovine fetoplacental vasculature. Am J Physiol 259:H464-H472

28. Assali NS, Holm LW, Sehgal N 1962 Regional blood flow and vascular resistance of the fetus in utero. Am J Obstet Gynecol 83:809-817

29. Dawes GS 1968 Fetal and Neonatal Physiology. Year Book Medical Publishers, Chicago, pp 97-99, 177-179

30. Mohammad MA, Sparrow MP 1988 Changes in myosin heavy chain stoichiometry in pig tracheal smooth muscle during development. FEBS 228:109-112

31. Frid MG, Shekhonin BV, Koteliansky VE, Glukhova MA 1992 Phenotypic changes of human smooth muscle cells during development: late expression of heavy caldesmon and calponin. Dev Biol 153:185-193

32. Simons M, Rosenberg RD 1992 Antisense nonmuscle myosin heavy chain and c-myb oligonucleotides suppress smooth muscle cell proliferation in vitro. Circ Res 70:835843

33. Chamley-Campbell J, Campbell GR, Ross R 1979 Smooth muscle cell in culture. Physiol Rev 59:1-61 